\title{
GNSS Based Real Time Train Monitoring: A Web Approach
}

\author{
Mohd Shoab \\ Department of Civil Engineering \\ IIT Roorkee, India
}

\author{
Kamal Jain \\ Professor, Department of Civil \\ Engineering \\ IIT Roorkee, India
}

\author{
M. Shashi \\ Asst. Professor, Department of \\ Civil Engineering \\ NIT Warangal, India
}

\begin{abstract}
Global Navigation Satellite Navigation System (GNSS) is widely used for surveying, navigation, timing, positioning and Tracking. This is a technique which is highly precise, real time, continuous and work in all weather conditions for providing position and navigation information. Two GNSS systems are currently fully operational, United States GPS and Russian GLONASS. GNSS is used in transportation industry for monitoring various types of vehicles like, aircrafts, ships, trains, buses etc. In the industrial and public transportation, railway is widely used by people in the world. Monitoring the trains is concern with the security and safety. In this paper, a GNSS based web application is proposed for monitoring trains. GNSS provide navigation and positioning information of a train. This web application is developed in C\#.net using Microsoft Visual Studio 2010.
\end{abstract}

\section{Keywords}

GNSS, GPS, GLONASS, navigation, positioning, trains, web application.

\section{INTRODUCTION}

Global Navigation Satellite System (GNSS) is a system of satellites that provide autonomous geo spatial positioning with global coverage (Someswar G. Manoj et. al., 2013, https://en.wikipedia.org/wiki/Satellite_navigation). The GNSS receiver calculate its precise position along with time, which can be used for scientific experiments. Only United States Global Positioning System (GPS) and Russians Global Orbital Navigation Satellite System (GLONASS) are fully operational GNSS. GNSS is widely used for surveying, navigation, timing, positioning and Tracking.

Railway is commonly used by people in industrial and public transportation. In transportation industry Reliability, Availability, Maintainability, and Safety are the key factors. Considering several parameters such as transferring huge amount of goods and passengers with a high level of security and saving of fuel as well as less environmental impacts have been considered by decision makers and transportation experts (Alaei Abbasali Jandaghi and Delavar Mahmoud Reza, 2003). Railway industry has a valuable role in economic development of each country and Indian Railways is the largest rail network in Asia and the world's second largest under one management. Crisscrossing the country's vast geographical spread, Indian Railway is a multi-gauge, multi-traction system covering over 1 lakh track (Shoab Mohd et. al., 2013).

Real time system can be categorized into two categories 1) hard real time system, 2) soft real time system. In hard real time system the timing is critically important and may not be sacrificed for other gains like control system of nuclear power plant. In soft real time system timing is important but not so critical like computerized banking, ticket reservation etc. (Chakraborty Alapan, 2009). To specify, design and analyze real time system, large number of formula methods has been implemented from several years. Real time tracking of an object is difficult but useful concept in today's scenario. Many technologies are there for tracking the position of a train during its journey, GNSS is one of them. GNSS is the technology that is used to locate the coordinates of train.

In India where trains are consistently late by several reasons, it become very impressive to develop a web application for monitoring trains in real time. Indian railway is using manual methods to monitor the position of train like signals are manually operated by level crossing and staff on instructions by telephone from the nearest railway station. The information about train to public waiting on platform or home is dependent on manual process. There is always a chance for abdication of the duty and delay in the information traversing due to this manual process. By this scenario passengers have to wait for unspecified time. (Patil Santosh B. and Walli Rupal M., 2012). The current system only gives the position of a train in between two railway stations but can't detect the real time position of the train where it is right now (Arshiya et. al., 2013)

Currently Indian railway providing train running information by two websites, http://www.trainenquiry.com and http://railradar.trainenquiry.com/. Both websites are not providing real time train location information because these websites are not using GNSS technology. These websites are providing train location information from station to station, not between stations, so that user don't know where is the train between stations.

To overcome the above situation a GNSS based web application is developed which provide real time location of trains on Google Maps along with train speed. Integration of GNSS and web technologies like Google maps, web browser and internet offer a low cost train monitoring solution, user's computer require only a web browser. This web application provides the solution for emergency response facility to access train location information (Boyle Frank and Union Switch \& Signal Inc.). This web application using previously developed web service (Shoab Mohd et. al., 2013), which provides real time train location information. User need to login in the web application for monitoring the trains. Users are categorized into two category 1) Administrator, 2) General user. The administrator have all the rights to add/edit users or trains and the general user can only monitor the selected train only. 


\section{DESIGN AND DEVELOPMENT}

Design and development of GNSS based web application for monitoring trains include integration of the web service which provide real time location information of a train and designing the web interface architecture which can show the real time position of a train on Google Map. The design and development of the web application utilize client server transections where the client makes a request to the server and server gives result back to the client (Sugumaran Ramanthan et. al., 2000).

\subsection{Design}

Designing an effective web site requires more than just gathering relevant information and posting it on the web. Like a good paper or research presentation, a quality web project demands as much attention to the selection, organization, and presentation of material as to the underlying research itself (http://www.umich.edu/ ece/resources/design.html). Basic HTML and CSS which are by default provided by visual studio 2010 for the master page and other web pages are used. HTML is used to structure the content and the CSS is used for formatting structured content. HTML stands for Hyper Text Markup Language which makes it possible to present information in the web environment. HTML is written in the form of HTML elements consisting of tags enclosed in angle brackets like $\langle\mathrm{html}\rangle$, within the web page content. The browser does not display the HTML tags, but uses the tags to interpret the content of the page. It can embed scripts written in languages such as JavaScript which affect the behavior of HTML web pages (https://en.wikipedia.org/wiki/HTML). CSS stands for Cascading Style Sheets and gives both web developer and user more control over how pages displayed. CSS allows designer to specify things like font, font size, columns, font style and so on. CSS enable us to change the appearance and layout of all pages in a web site just by editing a single file. CSS, provided by the visual studio 2010 is used to style the web pages of developed web application.

\subsection{Development}

Web development is process of developing a web site for the internet or an intranet that includes web design, web content development, client-side/server-side scripting, and web server configuration. Among web professionals, web development usually refers to the main non-design aspects of building web sites like writing markup and coding. Web development ranges from the simplest tasks to the highly professional and complex applications. This can include the very simple plaintext page to the complicated applications of the web-based internet, or social networking (http: //www.yourmaindomain. com/web-articles/what-is-web-development.asp).

The web development can be split into two main categories, the Client Side Coding and the Server Side Coding. The client side coding refers to the code scripted for the end-client that reflects on the clients' terminal. This type of coding is known as Front-end script. It is written in various scripts including Ajax, Adobe Flash, Adobe Flex, JavaScript, JavaFx, Microsoft's Silverlight, and HTML. There is no need to add any additional software on the server but the end-user's browser must assess the scripting language in which they are written. On the other hand Server Side Coding is the script that does not visually seen on the client's terminal but it supports the whole program and software. It is stored on the server and it need the software support on the server. If there is no software installed on the server, the server-side script cannot run and it will also not support the client-side script. Server-side coding can be written in many languages that include ASP, ColdFusion, CGI and/or Perl, C Server Scripts, Java, Lotus Domino, PHP, Python, Django, Ruby, Ruby on Rails, Smalltalk Seaside, AIDA/Web, SSJS Server-Side JavaScript, Websphere, .NET and many more.

The combo of client side and server side coding means the need of both scripts in an application. Without the mutual support of each other, the application cannot run properly. Usually medium to large and dynamic websites are created using both scripts (http://www.roseindia.net/webdevelopment /Webdevelopment-Introduction.shtml). Both client side and server side coding is used to develop this web application.

C\# and java script in visual studio 2010 are used to develop this web application. On server side C\# is used and on client side java script is used to show the real time train location information on Google Maps. Google Maps API is used to show the Google Maps into web browser. Previously developed web service provide real time train location information to this web application (Shoab Mohd et. al., 2013). Users can be categorized into two category administrator and general user. Administrator can monitor trains as well as he/she has full rights to add/edit/delete trains or users and general user can only monitor the selected train. Before using the services which are provided by the developed web application, users must register themselves on the developed web application. After registration user can login and select the train from the train list and monitor the selected train on Google Maps. The developed web application provide real time train tracking with the latency of 20 seconds and accuracy of 5-10 meters which is depends on remote GNSS device. Figure 1 shows the data flow of developed web application working.

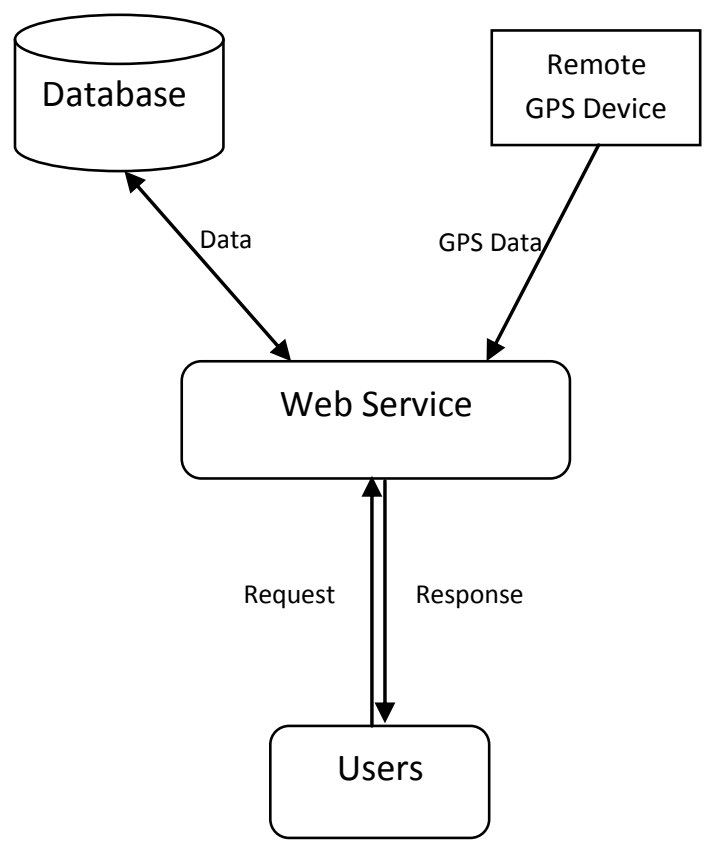

Fig 1: Data flow of developed application.

\subsubsection{Architecture}

System architecture is the key element of any application. The system architecture defines how the pieces of the application interact with each other, and what functionality each piece is responsible for performing. In the web world we often build 
applications in the distributed environment. A distributed application utilizes the resources of multiple machines or at least multiple process spaces, by separating the application functionality into more manageable groups of tasks that can be deployed in a wide variety of configurations. Dividing up an application in this manner results in the creation of a series of application layers or tiers, each of which is responsible for an individual, or atomic, element of the application's processing. Tiered applications can be characterized by the number of layers that information will pass through. Each layer generally runs on a different system, or in a different process space on the same system, than the other layers (http: //technet.microsoft.com/en-us/library/bb727121.aspx). Tiered applications can be categorized into two categories, Two Tier Application and Three Tier or N-Tier Application. In Two Tier application typically there is a client and a network server that contains the database. In the Three Tier or N-Tier architecture the business logic is separated from the user interface and the data source.

The Developed web application follows Three Tier architecture to process the user's request. User send a request about train location information to web server which contains the web application, this web application check the authenticity of user and if user is authentic then forward user's request to another web server which contains the web service. The web service communicate with the database and send train location information back to the user via web server which contain web application. Figure 2 shows the developed web application architecture.

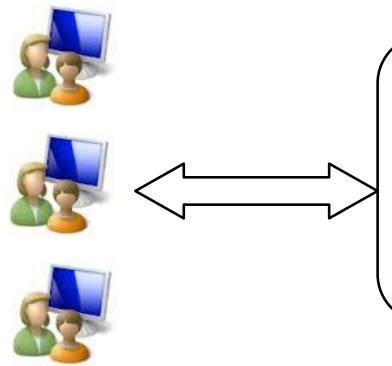

Users

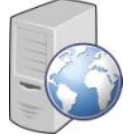

Web Application

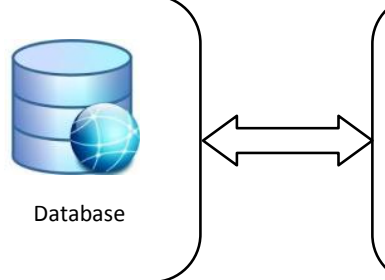

Web Application Server

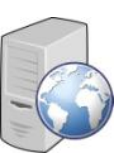

Web Service

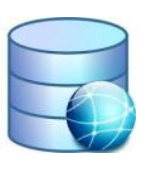

Database
Web Server Containing Web Service

Fig 2: Three Tier architecture of developed web application.

\section{TEST AND RESULTS}

\subsection{Test}

Web testing focuses testing of web application that can help address issues before the system is revealed to the public. Issues such as the security of the web application, the basic functionality of the site, its accessibility as well as readiness for expected traffic, number of users and the ability to survive a massive spike in user traffic can be detected in web testing (http://en.wikipedia.org/wiki/Web_testing). Test of functionality and accessibility developed web application was done in the Firefox web browser and it passes all the test with satisfactory results. It is providing real time train location in every 20 seconds on Google Maps and not compromising with this latency. User can get the best view of developed web application with the Mozilla Firefox.

\subsection{Results}

The developed web application produced excellent result and train can be monitored in the web environment. On a commercial foresight the web application, once live, will be able to completely monitor the trains effectively. Before using services of developed web application users must register themselves in developed web application by filling registration form, after that user can login into developed web application, the login page is shown in Figure 3 with registration form link. After login, the train list page open which is shown in Figure 4. If the user is administrator the user can monitor and add/edit or delete trains by clicking on train number and Add Train link or Delete link otherwise if the general user login, user can only monitor trains by clicking on train number in train list. Different location of train 14318 running between Roorkee and Saharanpur is shown in Figure 5A, 5B and 5C respectively. Another train 15011 also running between Roorkee and Saharanpur was monitored by the developed web application which is shown in Figure 6A, 6B and 6C.

\section{CONCLUSION}

It is an attempt to utilize the features of web technology in railway industry to monitor trains in web environment. The developed web application is reliable, cost effective and fully automatic train monitor application in compression with traditional train monitoring. The developed a web application is capable to show the real time train location on Google Maps. This type application plays a very important role for fast response teams and recovery teams if any railway disaster happen. In India trains are consistently late, so that passengers have to wait for unspecified time. But using the developed web application passengers can get real time train location on their computers or mobile phones so that there is no need to wait for unspecified time. This web application provides the train monitoring solution for train operator as well as the general users also.

\section{ACKNOWLEDGMENTS}

The authors would like to thank Google Inc. for providing free Google Maps API to integrate and utilize the features of Google Maps into the developed web application. 


\section{REFERENCES}

[1] Alaei Abbasali Jandaghi and Delavar Mahmoud Reza, (June, 2003) "Integration of GPS and GIS for Railway Accident Management" Preceding Conference Simtect's, Adelaide, Australia.

[2] Arshiya, S Kehkeshan Jalall and Banu Sufia (April, 2013). "Speed and Position Control of Train System Using GPS", IOSR Journal of Electronics and Communication Engineering (IOSR-JECE), 2278-2834.

[3] Basic Web Designing Principals by "http://www.umich.edu/ ece/resources/design.html". Accessed on $8^{\text {th }}$ June, 2013.

[4] Boyle Frank, Union Switch \& Signal Inc. (April, 2008). "Monitoring Train Position to Improve Emergency Response" Project Report on Innovations Deserving Exploratory Analysis (IDEA) Program.

[5] Chakraborty Alapan (October 2009). "Fault Tolerant Fail Safe System for Railway Signaling", Proceedings of the World Congress on Engineering and Computer Science 2009 Vol II.

[6] Component and Web Application Architecture by "http://technet.microsoft.com/enus/library/bb727121.aspx". Accessed on $13^{\text {th }}$ June 2013.

[7] HTML by "https://en.wikipedia.org/wiki/HTML". Accessed on $8^{\text {th }}$ June, 2013.

[8] Live train tracker by "http://railradar.trainenquiry.com/". Accessed on $15^{\text {th }}$ June, 2013.

[9] National Train Enquiry System by "http://www.trainenquiry.com". Accessed on $15^{\text {th }}$ June, 2013.
[10] Patil Santosh B. and Walli Rupal M. (February, 2012). "Design and Development of Fully Automatic AT89C52 Based Low Cost Embedded System for Rail Tracking", International Journal of Electronics, Communication \& Soft Computing Science and Engineering (IJECSCSE).

[11] Satellite Navigation by "https://en.wikipedia.org/ wiki/Satellite_navigation". Accessed on $30^{\text {th }}$ May 2013 .

[12] Shoab Mohd, Jain Kamal and Shashi M (January, 2013). "Development and Implementation of Web Service for Logging and Retrieving Real Time Train Location Information", International Journal of Soft Computing and Engineering (IJSCE), 2231-2307.

[13] Someswar G. Manoj, Rao Surya Chandra T.P. and Rao Dhanunjaya Chigurukota (February, 2013). "Global Navigation Satellite Systems and Their Applications", International Journal of Software and Web Sciences, pp 17-23, 2279-0071.

[14] Sugumaran Ramanthan, Davis H. Curt, Meyer Jim and Prato Tony (July, 2000). "High Resolution Digital Elevation Model and a Web-Based Client-Server Application for Improved Flood Plain Management", Geoscience and Remote Sensing Symposium, 2000 Proceedings. IGARSS 2000. IEEE 2000 International.

[15] Web Development Introduction by "http://www.roseindia.net/webdevelopment/Webdevelop ment-Introduction.shtml”. Accessed on $9^{\text {th }}$ May, 2013.

[16] Web testing by "http://en.wikipedia.org/wiki/Web_ testing". Accessed on $15^{\text {th }}$ June, 2013.

[17] What is Web Development by "http://www.yourmaindo main.com/web-articles/what-is-web-development.asp". Accessed on $9^{\text {th }}$ May, 2013. 


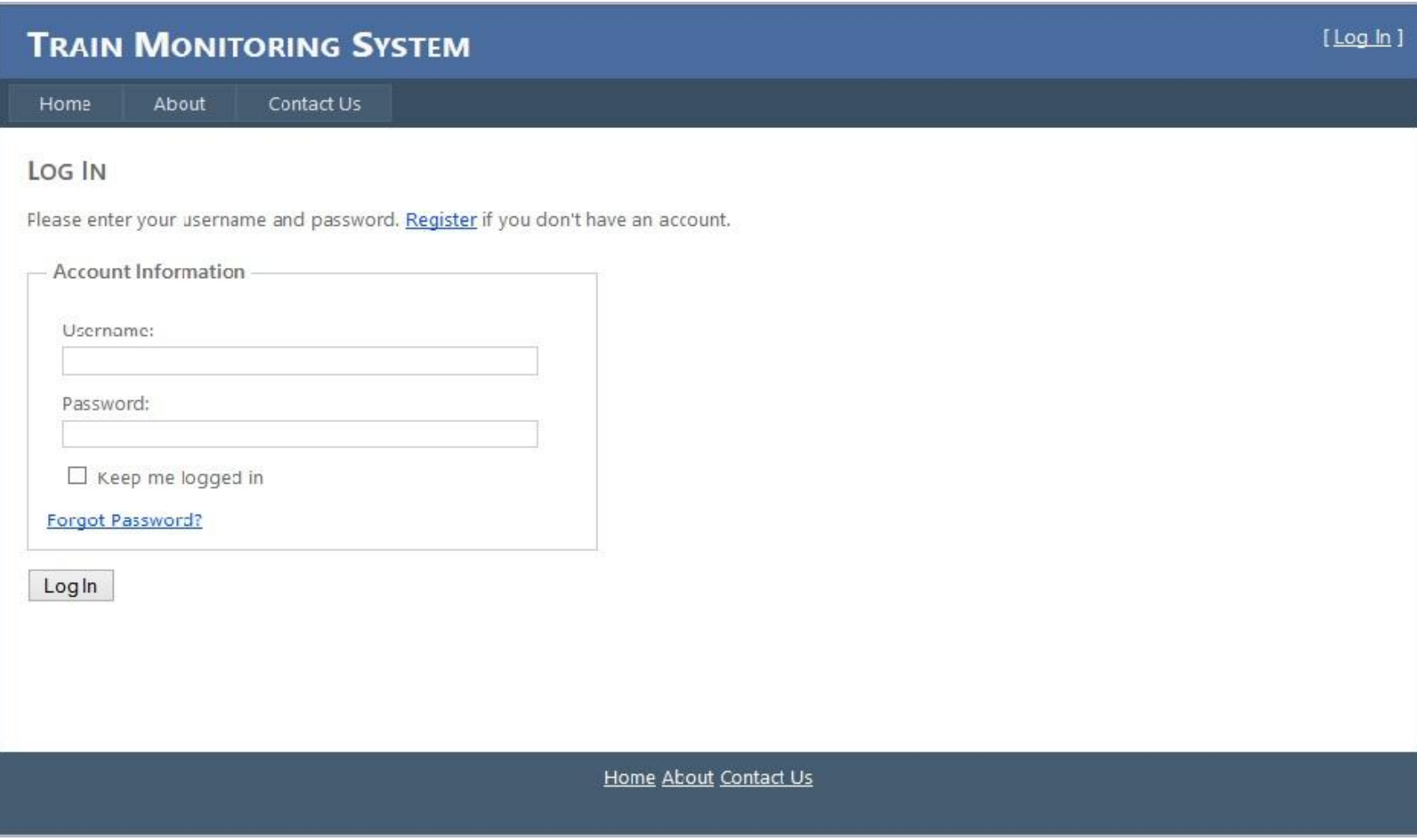

Fig 3: Login page for users with registration link, by which users can register themselves.

\section{Train MONITORING SYSTEM}

\section{Home About contact Us:}

\section{Add Train}

Trains List

\begin{tabular}{|c|c|c|c|c|c|c|c|c|}
\hline $\begin{array}{c}\text { Train } \\
\text { Number }\end{array}$ & Name & Type & Origin & Destination & $\begin{array}{c}\text { Departure } \\
\text { Time }\end{array}$ & $\begin{array}{l}\frac{\text { Arrival }}{\text { Time }} \\
\end{array}$ & $\begin{array}{l}\text { Travel } \\
\text { Time }\end{array}$ & Delete \\
\hline 14318 & $\begin{array}{l}\text { DDN INDB } \\
\text { EXP }\end{array}$ & $\begin{array}{c}\text { Mail/Express } \\
\text { /Superfast }\end{array}$ & Roorkee & Saharanpur & $8: 30$ & 9:30 & 01:00 & Delete \\
\hline 15011 & $\begin{array}{l}\text { LJN CDG } \\
\text { EXP }\end{array}$ & $\begin{array}{l}\text { Mail/Express } \\
\text { /Superfast }\end{array}$ & Roorkee & Saharanpur & $11: 20$ & 12:15 & $00: 55$ & Delete \\
\hline 19020 & $\begin{array}{l}\text { DEHRADUN } \\
\text { EXP }\end{array}$ & $\begin{array}{c}\text { Mail/Express } \\
\text { /Superfast }\end{array}$ & Roorkee & Saharanpur & $14: 50$ & $15: 50$ & $01: 10$ & Delete \\
\hline$\underline{54251}$ & $\begin{array}{l}\text { LKO SRE } \\
\text { PAS }\end{array}$ & $\begin{array}{l}\text { Mail/Express } \\
\text { /Superfast }\end{array}$ & Roorkee & Saharanpur & $17: 15$ & $18: 30$ & $01: 15$ & Delete \\
\hline
\end{tabular}

Fig 4: Train list page for administrator. 


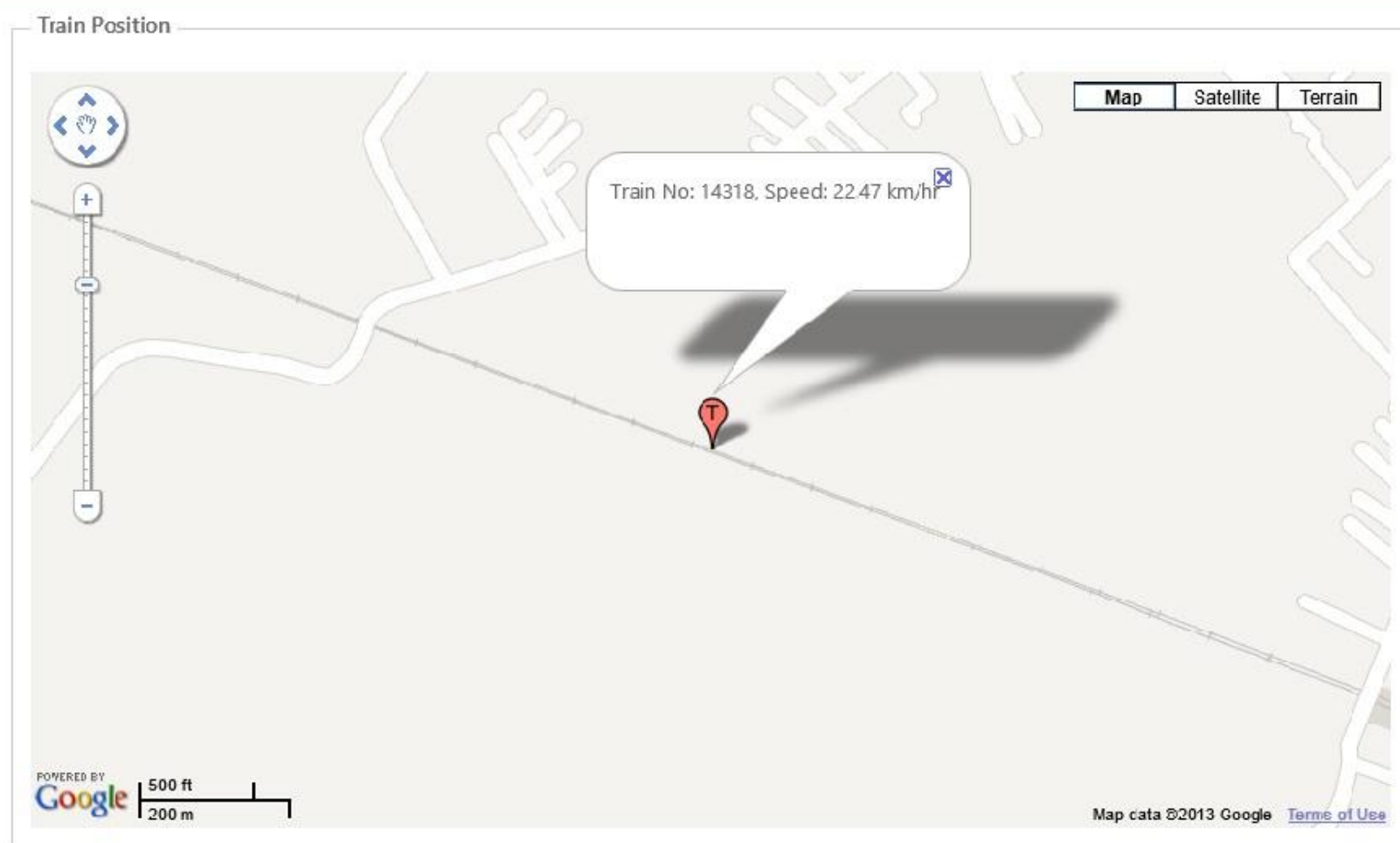

Fig 5A: Train 14318 position on Google Maps on $2^{\text {nd }}$ June 2013 at 8:34:44.

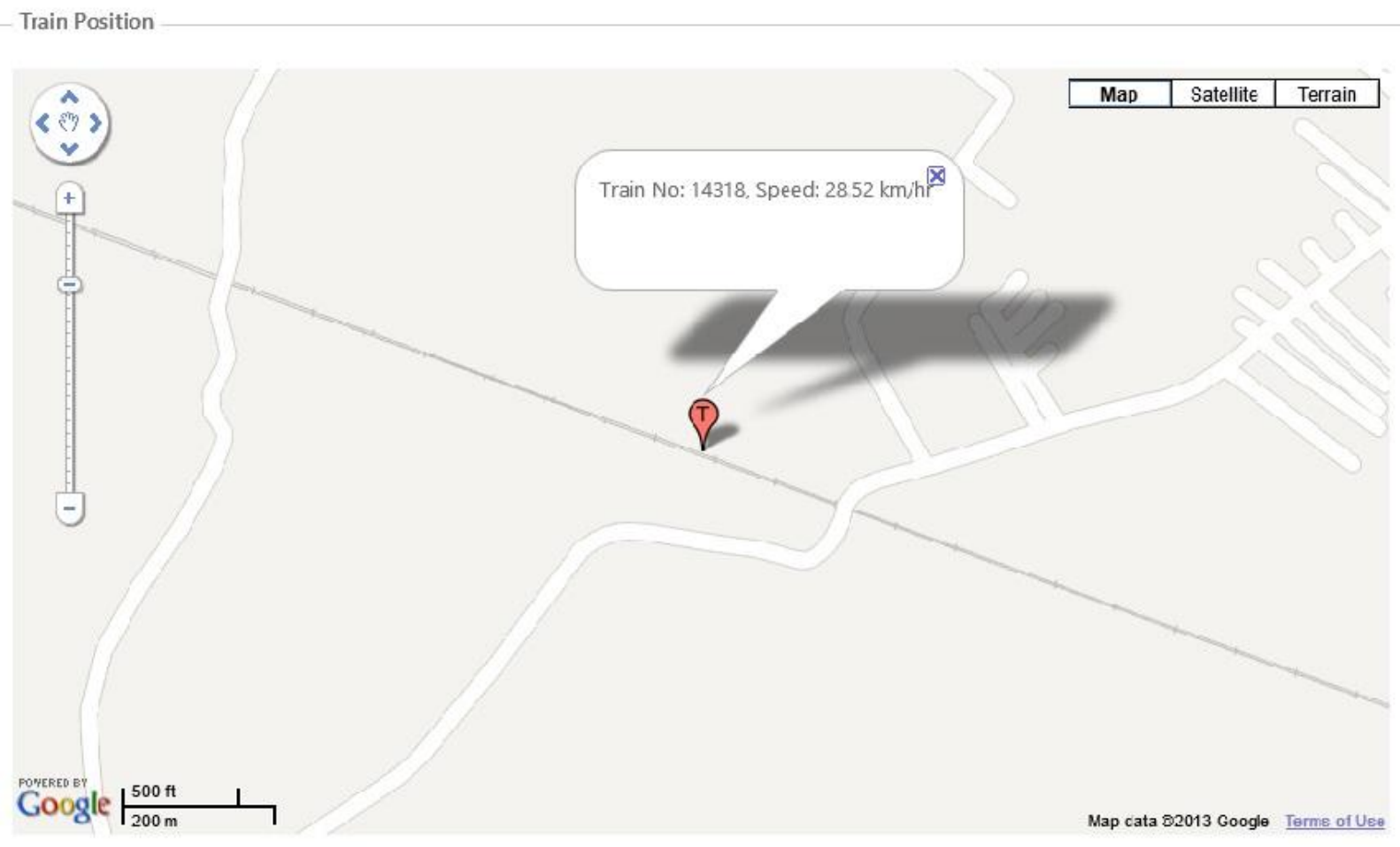

Fig 5B: Train 14318 position on Google Maps on $2^{\text {nd }}$ June 2013 at 8:35:31. 


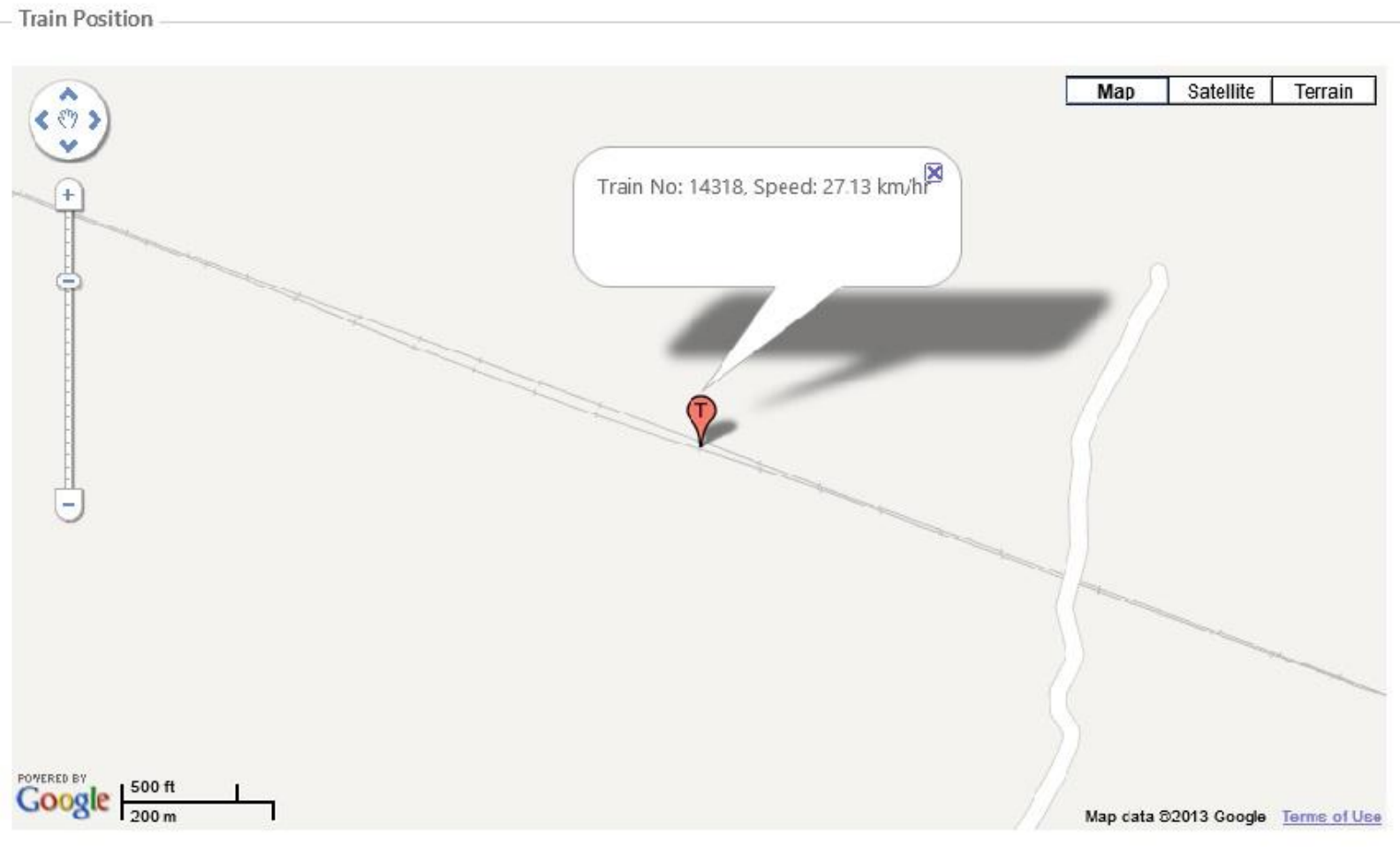

Fig 5C: Train 14318 position on Google Maps on $2^{\text {nd }}$ June 2013 at 8:36:07.

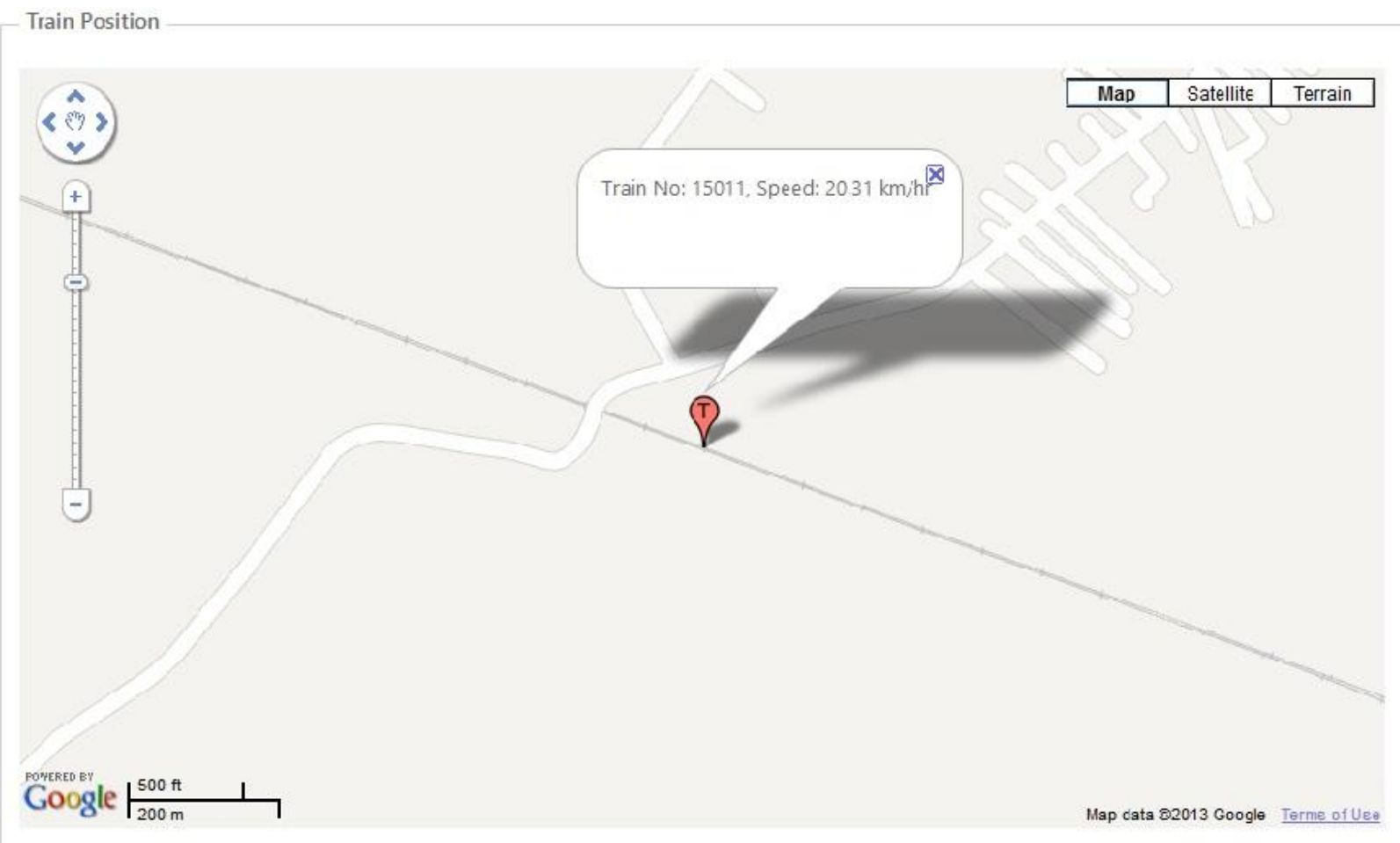

Fig 6A: Train 15011 position on Google Maps on $2^{\text {nd }}$ June 2013 at 11:36:21. 


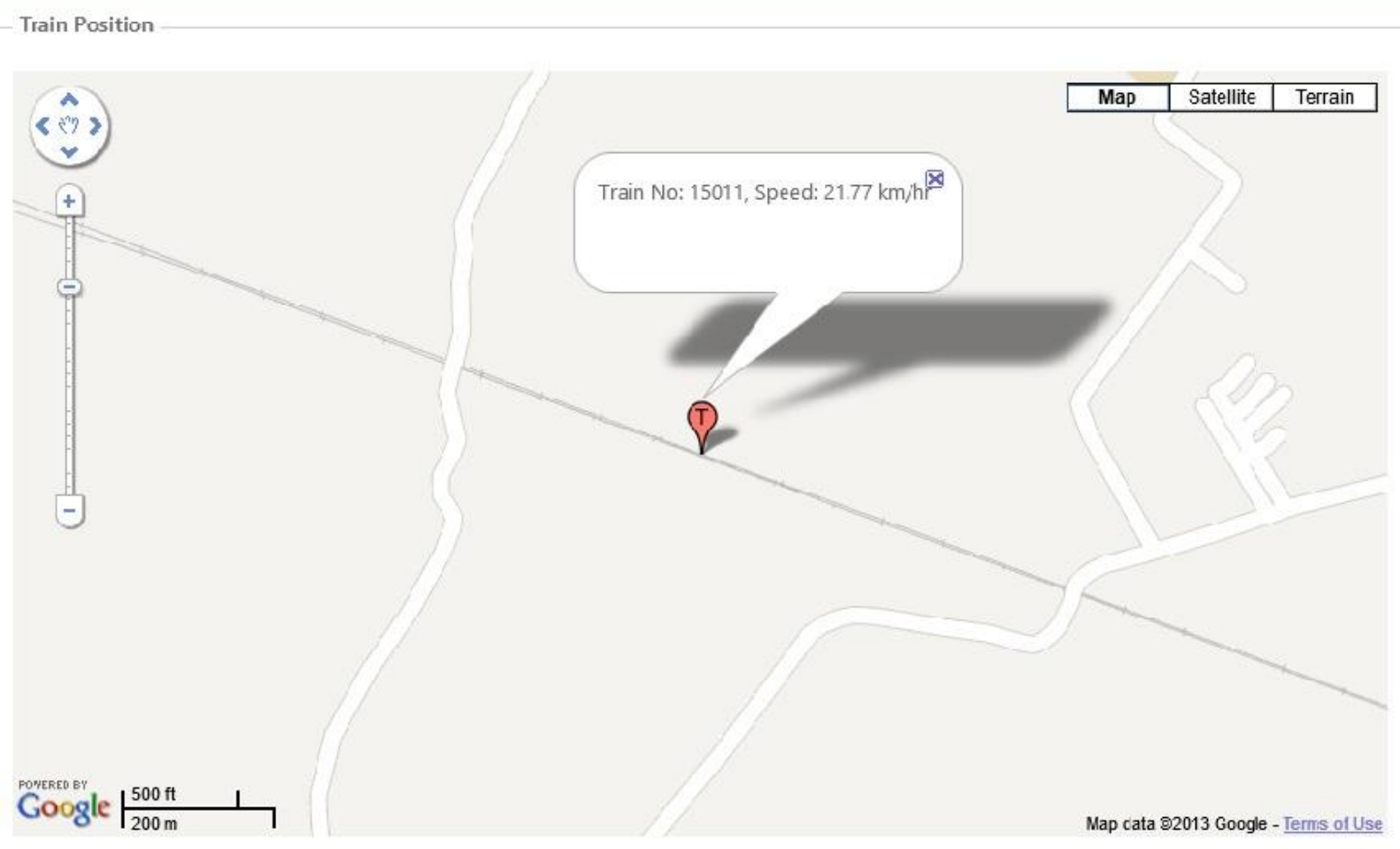

Fig 6B: Train 15011 position on Google Maps on $2^{\text {nd }}$ June 2013 at 11:36:58.

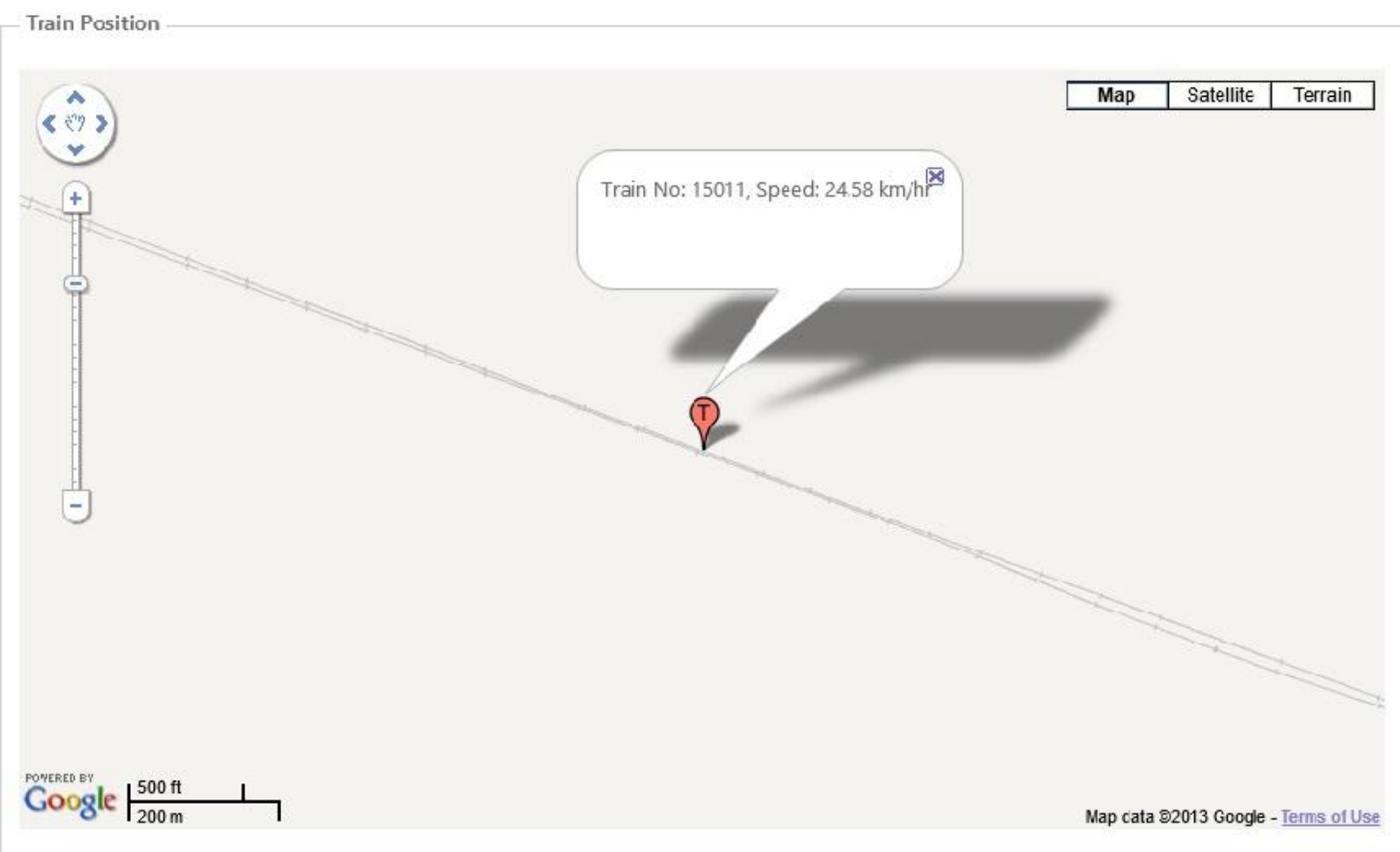

Fig 6C: Train 15011 position on Google Maps on $2^{\text {nd }}$ June 2013 at 11:37:54. 